\title{
Review article- Role of Chitosan in Wound Healing - a Review of the Recent Advances
}

\author{
N Gokarneshan* \\ Department of Textile Technology, Park College of engineering and technology, India
}

Submission: November 01, 2017; Published: November 13, 2017

*Corresponding author: N Gokarneshan, Professor and Head, Department of Textile Technology, Park college of engineering and technology, Coimbatore, Tamil Nadu, India, Email: advaitcbe@rediffmail.com

\begin{abstract}
During the past decade, much interest has been developed in biopolymer based materials due to their biocompatible, biodegradable, non-toxic and non-allergic nature. Studies have been done on the key features of inherent properties of chitosan, their modification, and its use in biomedical engineering particularly toward anti inflammatory and wound healing. Chitin and chitosan with beneficial biological and antimicrobial properties and high valuable potential for wound healing are attractive for wound care. The chitin nanowhiskers applications are used mainly as reinforcing polymer nanocomposites, but also to prepare scaffolds, hydrogels and wound dressings, as adsorbents in industry, water purification, for protein immobilization, transformation of bacteria by exogenous genes, stabilization of oil-in-water emulsion and nematic gels, formation of $\mathrm{CaCO}_{3}$ /chitin-whisker hybrids and as carbon precursors.
\end{abstract}

Keywords: Chitosan; Biopolymer; Nano whiskers; Wound dressings; Biomedical applications

\section{Introduction}

In all biomedical applications today, polymers are playing an important role today. Many notable advances in technology have followed exploitation of the properties offered by new polymeric materials like blends and composites [1-5]. Various types of biopolymers particularly of carbohydrate origin have been found to have a very promising industrial application in various forms and chitosan is one such [6]. Chitin is the second most abundant biopolymer after cellulose, existing in the exoskeletons of crabs, prawns, and insects and the cell walls of fungi. Although chitin is produced in Nature at a rate of 1010 to 1011 tons per year, most chitin is thrown away as commercial waste [7].

This is obviously due to the low workability of the biopolymer, since commercially available chitin powder is not soluble in any solvent but precipitates immediately. A large body of knowledge exists today on the use of chitosans as safe biomaterials for a variety of applications: there are recent review articles in biomedical sciences and in pharmaceutical sciences [8-12]. Chitin and chitosan with beneficial biological and antimicrobial properties and high valuable potential for wound healing are attractive for wound care. In recent years, a large number of research groups are dedicated to produce a new, improved wound dressing by synthesizing and modifying biocompatible materials [13-15].

\section{Role of chitosan based scaffolds in wound healing}

The different properties like antimicrobial, anti inflammatory and bio medical applications of chitosan based materials particularly wound dressings have been explored. Owing to its antimicrobial and anti-inflammatory nature chitosan has been shown to be a potential biomaterial to be used in potential wound healing [16]. Effective dressings should have characteristics optimized for a particular type of wound at a reasonable low cost and with minimum inconvenience to patients. Many results have been reported, but complete and standard characterization of such materials is required.

Hence it is necessary to manipulate the physical properties of identified systems to achieve such objectives. Although a lot of literature is available on chitosan and modified chitosan (blends/composites/derivatives) for wound healing, there are many challenges which need to be explored in process of wound healing. The role of chitosan has been studied in the following areas:
a) Modifications of chitosan for clinical applications
b) Antimicrobial nature of chitosan
c) Anti-inflammatory nature of chitosan 
d) Biomedical applications of chitosan

e) Wound healings of chitosan

f) Chitosan with synthetic /natural polymer blend scaffolds in wound healings

g) Chitosan based composite scaffolds in wound healings

h) Chitosan based sponges in wound healing

i) Chitosan based oil immobilized scaffolds in wound healings

j) Chitosan based extract immobilized scaffolds in wound healings

k) Chitosan based drug loaded scaffolds in wound healings

The above studies are expected to provide insights on the use of these important chitosan based materials for researchers working in the field of biomedical and pharmaceutical sciences.

\section{Chitin and chitosan nano fibres}

Chitin NFs were prepared from crab shells, prawn shells, squid pen, and mushrooms by a series of extraction treatments followed by mechanical treatment using a grinder or a high-pressure waterjet disintegration system. Several chemical modifications of chitin NF surfaces were achieved: acetylation, deacetylation, phthaloylation, naphthaloylation, maleylation, chlorination, TEMPO-mediated oxidation, and graft polymerization [17-24]. Modification is a promising and effective way to design functional materials. Moreover, chitin NFs have powerful biological activities and several applications were proposed in biomedical field [25-29]. For instance, they have anti-inflammatory actions via the suppression of NF- $\mathrm{\kappa B}$ and MCP1 activations and they suppress fibrosis in an acute ulcerative colitis mouse model, indicating that chitin NF is potentially a novel medicine or functional food for patients with inflammatory bowel disease [30,31]. Furthermore, the application of chitin NF to skin improved the epithelial granular layer, increased granular density, and resulted in lower production of TGF- $\beta$, indicating that chitin NFs can be incorporated into the manufacture of cosmetics or textiles $[32,33]$. Consequently, we expect that chitin $\mathrm{NF}$ with the above-mentioned properties will be widely used as a novel bio-material in the near future.

\section{Chitin and chitosan in wound dressing}

Chitin and chitosan have an accelerating effect on the wound healing process. A number of studies have demonstrated that chitin and chitosan accelerated wound healing. Chitin and chitosan have been used as nano fibres, gels, scaffolds, membranes, filaments, powders, granules, sponges or as a composite. The main biochemical activities of chitin and chitosanbased materials in wound healing are polymorph nuclear cell activation, fibroblast activation, cytokine production, giant cell migration and simulation of type IV collagen synthesis [34].
Nano fibre matrices have shown tremendous promise as tissue engineering scaffolds for skin substitutes. The advantages of a scaffold composed of ultrafine, continuous fibbers are oxygenpermeable high porosity, variable pore-size distribution, high surface to volume ratio and most importantly, morphological similarity to natural extracellular matrix (ECM) in skin, which promote cell adhesion migration and proliferation. Recent advances in process chemistry have made it possible to make chitin and chitosan nanofibril materials with more flexibility and useful for the development of new bio-related products [35].

\section{Application of chitin nanowhiskers}

Chitin can be extracted from biological tissues and dispersed in aqueous media to form colloidal suspensions of chitin nanowhiskers. The utilization of chitin nanowhiskers contributes to a healthy ecosystem, chitin being a renewable resource. Chitin nanowhiskers have drawn attention in various applications due to their properties like nanosized dimensions, high surface area, high absorptivity, biodegradability, nontoxicity, renewability, low density and easy modification. The intrinsic rigidity of chitin nanowhiskers, special rod-like and spindle-like morphology, strong interfacial interactions, and the percolation network organized by nanowhiskers contribute to optimized mechanical performance, thermal properties, solvent absorption, and barrier properties.

One key advantage is their high surface area that enables chitin nanowhiskers to interact effectively with cells, factors, proteins and other compounds. Chitin nanowhiskers possess a reactive surface covered with hydroxyl groups, giving the opportunity of chemical modification. Realization of functional modifications of chitin nanowhiskers under mild reactive conditions would greatly improve their practical utility for the future [36]. Chitin nanowhiskers can be used as environmentally friendly particulate bio fillers being compounded with many different kinds of polymer matrices. The reinforcing effect strongly depends on the aspect ratio of the chitin whisker, and therefore on its origin, as well as on the processing technique of the composite. Chitin nanowhiskers can form viable materials for biomedical areas, such as scaffolding and immobilizing bio molecules in the process of producing novel biosensors by using waste and cheap materials obtained from other industries. They also have applications in the cosmetics industry, mainly for the ordered regeneration of wound tissues and as dermal fillers.

\section{Conclusion}

Chitosan has been shown to be a potential biomaterial to be used in wound healing due to its anti inflammatory and antibacterial nature. Effective dressings should have characteristics optimized for a particular type of wound at a reasonable low cost and with minimum inconvenience to patients. There is need to manipulate the physical properties of identified systems to achieve such objectives. Although a lot of literature is available on chitosan and modified chitosan 


\section{Global Journal of Addiction \& Rehabilitation Medicine}

(blends/composites/derivatives) for wound healing, there are many challenges which need to be explored in process of wound healing. Chitin NFs have powerful biological activities and several applications were proposed in biomedical field. For instance, they have anti-inflammatory actions via the suppression of NF- $\kappa \mathrm{B}$ and MCP- 1 activations and they suppress fibrosis in an acute ulcerative colitis mouse model, indicating that chitin NF is potentially a novel medicine or functional food for patients with inflammatory bowel disease.

Furthermore, the application of chitin NF to skin improved the epithelial granular layer, increased granular density, and resulted in lower production of TGF- $\beta$, indicating that chitin NFs can be incorporated into the manufacture of cosmetics or textiles. Consequently, we expect that chitin NF with the above-mentioned properties will be widely used as a novel biomaterial in the near future. In the area of wound management, the use of chitin, chitosan and its derivative is immense. Chitin and chitosan have excellent properties such as biodegradability, bio-compatibility, and non toxicity and have been shown to enhanced wound healing in animals and humans. To improve the potential of chitin and chitosan for wound dressing applications, further studies are needed. Chitin nanowhiskers can prove useful in biomedical fields, like scaffolding and immobilizing bio molecules in the process of producing novel biosensors by using waste and cheap materials obtained from other industries. They also find use as dermal fillers particularly in the ordered regeneration of wound tissues.

\section{References}

1. Kittur FS, Harish Parashant KV, Udaya sankar K, Tharanathan RN (2002) Characterization of chitin, chitosan and their carboxymethy derivatives by differential scanning calorimetry. Carbohydrate polymer 49(2): 185-193

2. Muzzarelli RAA, Muzzarelli C (2005) Chitosan chemistry: Relevance to the biomedical sciences. Advanced polymer science 186: 151-209.

3. Qin Y, Xing R, Liu S, Li K, Meng X (2012) Novel semithiocarbazone chitosan derivatives: preparation, characterization and antifungal activity. Carbohydrate polymer 87(4): 2664.

4. Chee KK (1990) Determination of polymer-polymer miscibility by viscometry. European polymer journal 26: 423

5. Sun Z, Wang W, Feng Z (1992) Criterion of polymer-polymer miscibility determined by viscometer. Eur Polym J 51: 1259.

6. Singh AV (2011) Biopolymers in drug delivery: a review. Pharmacology online 1: 666-674.

7. Gopalan NK, Dufresne A (2003) Crab shells chitin whiskers reinforced natural rubber nanocomposites. Processing and swelling behaviour. Biomacromolecules 4(3): 657-665.

8. Park BK, Kim MM (2010) Applications of chitin and its derivatives in biological medicine. Int J Mol Sci 11(12): 5152-5164.

9. Yang TL (2011) Chitin-based materials in tissue engineering: Applications in soft tissue and epithelial organ. Int J Mol Sci 12(3): 1936-1963.

10. Gupta B, Agarwal R, Alam MS (2010) Textile-based smart wound dressings. Indian J Fibre Textile Res 35: 174-187.
11. Laurienzo P (2010) Marine polysaccharides in pharmaceutical applications: An overview. Mar Drugs 8(9): 2435-2465.

12. 12. Kean T, Thanou M (2010) Biodegradation, biodistribution and safety of chitosan. Adv Drug Deliv Rev 62(1): 3-11.

13. Shibata H, Shioya N, Kuroyangi Y (1997) Development of new wound dressing composed of spongy collagen sheet containing dibutyryl cyclic AMP. J Biomater Sci Polym Ed 8(8): 601-621.

14. Draye JP, Delaey B, Van Den Voorde A, Van Den Bulcke A, De Reu B, et al. (1998) In vitro and in vivo biocompatibility of dextran dialdehyde cross-linked gelatin hydrogel films. Biomaterials 19(18): 1677-1687.

15. Ulubayram K, Nur Cakar A, Korkusuz P, Ertan C, Hasirci N (2001) EGF containing gelatin-based wound dressings. Biomaterials 22(11): 1345-1356.

16. Shakeel A, Ikram S (2016) Chitosan based scaffolds and their applications in wound healing. Achievements in the life sciences 10:27

17. Ifuku S, Morooka S, Morimoto M, Saimoto H (2010) Acetylation of chitin nanofibers and their transparent nanocomposite films. Biomacromolecules 11(5): 1326-1330.

18. Fan Y, Saito T, Isogai A (2010) Individual chitin nano-whiskers prepared from partially deacetylated $\alpha$ - chitin by fibril surface cationization Carbohydr Polym 79: 1046-1051.

19. Ifuku S, Suzuki N, Izawa H, Morimoto M, Saimoto H (2014) Surface phthaloylation of chitin nano fiber in aqueous media to improve dispersibility in aromatic solvents and give thermo responsive and ultraviolet protection properties. RSC Adv 4: 19246-19250.

20. Ifuku S, Suzuki N, Izawa H, Morimoto M, Saimoto H (2014) Surface maleylation and naphthaloylation of chitin nanofibers for property enhancement. React Funct Polym.

21. Dutta AK, Egusa M, Kaminaka H, Izawa H, Morimoto M, et al. (2015) Facile preparation of surface $\mathrm{N}$-halamine chitin nanofiber to endow antibacterial and antifungal activities. Carbohydr Polym 115: 342-347.

22. Fan Y, Saito T, Isogai A (2008) Chitin nanocrystals prepared by TEMPOmediated oxidation of $\alpha$-chitin. Biomacromolecules 9(1): 192-198.

23. Ifuku S, Iwasaki M, Morimoto M, Saimoto H (2012) Graft polymerization of acrylic acid onto chitin nanofiber to improve dispersibility in basic water. Carbohydr Polym 90(1): 623-627.

24. Ding F, Deng H, Du Y, Shi X, Wang Q (2014) Emerging chitin and chitosan nanofibrous materials for biomedical applications. Nanoscale 6(16): 9477-9493.

25. Wang Q, Zhang N, Hu X, Yang J, Du Y (2007) Chitosan/starch fibers and their properties for drug controlled release. Eur J Pharm Biopharm 66(3): 398-404.

26. Wang Q Zhang N, Hu X, Yang J, Du Y (2008) Chitosan/polyethylene glycol blend fibers and their properties for drug controlled release. J Biomed Mater Res A 85(4): 881-887.

27. Jang SI, Mok JY, Jeon IH, Park KH, Nguyen TT, et al. (2012) Effect of electrospun non-woven mats of dibutyryl chitin/poly(lactic acid) blends on wound healing in hairless mice. Molecules 17(3): 29923007.

28. Azuma K, Osaki T, Ifuku S, Saimoto H, Morimoto M, et al. (2014) Anti-inflammatory effects of cellulose nanofiber made from pear in inflammatory bowel disease model. Bioact Carbohydr Diet Fibre 3: $1-10$.

29. Azuma K, Osaki T, Wakuda T, Ifuku S, Saimoto H, Tsuka T, et al. (2012) Beneficial and preventive effect of chitin nanofibrils in a dextran sulfate sodium-induced acute ulcerative colitis model. Carbohydr Polym 87: 1399-1403. 
30. Azuma K, Osaki T, Ifuku S, Saimoto H, Tsuka T, et al. (2012) nanofibrils improve inflammatory and fibrosis responses in inflammatory bowel disease mice model. Carbohydr Polym 90(1): 197-200.

31. Ito I, Osaki T, Ifuku S, Saimoto H, Takamori Y, et al. (2014) Evaluation of the effects of chitin nanofibrils on skin function using skin models. Carbohydr Polym 101: 464-470.

32. Ito I, Osaki T, Tokuda K, Asami T, Takamori Y, et al. (2014) Effect of chitin nanofibril combined in rayon animal bedding on hairless mouse skin and on a three dimensional culture human skin model. J Chitin Chitosan Sci 2(2): 82-88.
33. Shinesuke Ifuku (2014) Chitin and Chitosan Nanofibers: Preparation and Chemical Modifications. Molecules 19(11): 18367-18380.

34. Mezzana P (2008) Clinical efficacy of a new chitin nanofibrils-based gel in wound healing. Acta Chir Plast 50(3): 81-84.

35. Mattioli Belmonte M, Zizzi A, Lucarini G, Giantomassi F, Biagini G, et al (2007) Chitin nanofibrils linked to chitosan glycolate as spray, gel and gauze preparations for wound repair. J Bioact Compat Polym 22: 525.

36. Mincea M, Negrulescu A, Ostafe V (2012) Preparation, modification, and applications of chitin nanowhiskers: A Review. Rev Adv Mater Sci 30: $225-242$.

\section{Your next submission with Juniper Publishers will reach you the below assets}

- Quality Editorial service

- Swift Peer Review

- Reprints availability

- E-prints Service

- Manuscript Podcast for convenient understanding

- Global attainment for your research

- Manuscript accessibility in different formats

( Pdf, E-pub, Full Text, Audio)

- Unceasing customer service

Track the below URL for one-step submission https://juniperpublishers.com/online-submission.php 